\title{
Use of home visits in pediatric severe asthma: randomized controlled trial*
}

\author{
O uso da visita domiciliar na asma grave pediátrica: estudo \\ experimental randomizado controlado \\ El empleo de la visita domiciliaria en el asma severa pediátrica: \\ estudio experimental randomizado controlado
}

How to cite this article:

Bresolini DSR, Queiroz MVNP, Gaspar GR, Reis LD, Araujo A, Lasmar LMLBF. Use of home visits in pediatric severe asthma: randomized controlled trial. Rev Esc Enferm USP. 2020;54:e03538. DOI: http://dx.doi.org/10.1590/S1980-220X2018039603538

\section{Daniela Soares Rosa Bresolini ${ }^{1}$ \\ Mônica Versiani Nunes Pinheiro de Queiroz ${ }^{1}$ \\ iD Guilherme Rache Gaspar ${ }^{1}$ \\ Luísa Diniz Reis ${ }^{1}$ \\ Alisson Araujo ${ }^{2}$ \\ Laura Maria de Lima Belizário Facury Lasmar ${ }^{1}$}

* Extracted from the dissertation: "Impacto das visitas domiciliares na asma grave pediátrica”, Programa de Pós- Graduação, Faculdade de Medicina, Universidade Federal de Minas Gerais, 2015.

${ }^{1}$ Universidade Federal de Minas Gerais, Faculdade de Medicina, Belo Horizonte, MG, Brazil.

${ }^{2}$ Universidade Federal de São João Del Rei, Campus Centro Oeste, Divinópolis, MG, Brazil.

\begin{abstract}
Objective: To evaluate the effectiveness of home visits in a group of children and adolescents with severe asthma by using the inhalation technique score and adherence rates to drug treatment. Method: A 12-month randomized controlled trial involving patients aged between three and 17 years under regular follow-up treatment at a pediatric pulmonology outpatient clinic of a university hospital in southeastern Brazil. A group of patients received only outpatient consultations and the other group received home visits from nurses in addition to outpatient consultations. The differences between groups were analyzed through the outcomes of inhalation technique scores and treatment adherence rate. Results: Participation of 29 patients. In the intervention group, there was a statistically significant increase in inhalation technique scores $(p<0.05)$ and elimination of critical errors between the first and the second evaluation, and results were maintained in the third evaluation. In the control group, there were no significant changes in inhalation technique scores. Rates of adherence to drug treatment in both groups did not rise. Conclusion: Home visits were effective for improving inhalation technique scores in patients with severe asthma. Brazilian Registry of Clinical Trials: RBR-8GZWZP
\end{abstract}

\section{DESCRIPTORS}

Asthma; Home Calls; Child; Adolescent; Medication Adherence; Inhalation. 


\section{INTRODUCTION}

Most children and adolescents with asthma use low or moderate doses of inhaled corticosteroids (IC) to control it ${ }^{(1)}$. Approximately 5\% of these patients have the severe form of the disease and need high doses of IC in association with one or more controllers. Severe asthma is rare, but these patients are at risk of severe exacerbations, adverse drug reactions, and account for almost $50 \%$ of all disease-related expenses, which justifies efforts to address this population ${ }^{(1)}$.

Potentially removable factors that prevent the adequate control of severe asthma should be addressed for the correct assessment of patients, including the evaluation of medication adherence rates and the inhalation technique (IT) used by patients ${ }^{(2)}$.

The inhalation technique is important for the proper drug deposition in the lungs. However, errors in the steps of correctly using IT are frequent ${ }^{(3)}$. The evaluation of potentially removable factors based on nurses' home visits (HV) were essential for their identification ${ }^{(4)}$. In a UK study, children were referred to a specialist asthma control center and visited by a nurse at their homes, and $80 \%$ of them had potentially modifiable factors ${ }^{(4)}$. Poor adherence, uncontrolled environment or errors in inhalation technique were among the causes of failure to control the disease ${ }^{(2)}$.

Only one study that used home visits for IT assessment was found ${ }^{(5)}$ and none used home visits to measure drug treatment adherence.

The aim of this study was to evaluate the impact of $\mathrm{HV}$ on inhalation technique and drug treatment adherence rates in children and adolescents with severe asthma.

\section{METHOD}

\section{STUdD DESIGN}

A randomized controlled trial involving children and adolescents with severe or difficult to control asthma.

\section{SCENARIO}

The study was conducted from January to December 2016 at the Multidisciplinary Center for Patients with Difficultto-Control Asthma (Portuguese acronym: CEMAD), Hospital das Clínicas of the Universidade Federal de Minas Gerais, Belo Horizonte (BH), Minas Gerais. This center serves children and adolescents from Belo Horizonte and the inlands of the state of Minas Gerais who are referred by specialists from secondary care services as a result of failure to control asthma.

\section{SELECTION CRITERIA}

Out of 53 patients from CEMAD, 19 patients were excluded, and 34 patients aged between three and 17 years living in Belo Horizonte or metropolitan region remained as participants of the study. Patients living in the inlands of the state were excluded because they depended on transportation provided by municipalities that has no guaranteed regularity, which would impair the follow-up in the study. Patients with other pathologies such as cystic fibrosis, ciliary dyskinesia, tuberculosis, post-infectious bronchiolitis obliterans, interstitial lung diseases and congenital pulmonary malformations were also excluded.

\section{SAMPLE DEFINITION}

Randomization was generated by computerized list and 17 patients were allocated in each group. In the intervention group, one patient withdrew after the first home visit, two refused to participate in the study and one was discharged from the service before the first home visit was performed. Therefore, 13 patients remained in the intervention group. In the control group, one patient refused to participate, hence 16 patients remained.

\section{Data collection}

The primary outcome was the assessment of the inhalation technique. The secondary outcome was the evaluation of clinical asthma control and adherence to inhaled corticosteroid use. The intervention group received routine outpatient care and the nurse's home visit. The control group received only outpatient care from the CEMAD team with evaluation by a different professional than the one who evaluated the intervention group. For the intervention group, three home visits with a 30 -day interval after the first visit and 60 days after the second visit were performed. In the control group, three consultations in the same periodicity were performed. Data from the first consultation were considered as baseline in the study. Home visits were scheduled according to availability of parents or the guardian, always with the patient's presence. During home visits, the availability, expiry date, conservation and accessibility of medication, the medication adherence rate, as well as the appropriate use of the asthma spacer were evaluated.

Issues related to environmental improvement, pathophysiology of asthma, the medications' mechanism of action and questions about the proposed treatment were also evaluated and addressed with the family and patients. All orientations were made individually, according to the questions, the environmental reality and the needs presented by the patient/family. For data analysis, it was always considered the information provided by the same person in order to avoid bias in the research.

The diagnosis and classification of asthma severity were registered in the medical records, based on criteria proposed by the American Thoracic Society (ATS) ${ }^{(6)}$.

To evaluate asthma control, the Childhood Asthma Control Test $(\mathrm{cACT})^{(7)}$ was used for children aged four to 11 years, and the Asthma Control Test $(\mathrm{ACT})^{(8)}$, was used for children over 12 years old. If the score was below 20 points, asthma was classified as uncontrolled ${ }^{(7-8)}$.

To measure adherence both in the intervention and control groups, patients or guardians were instructed to write on the medicine canister the starting use date of the IC and the number of doses through the dose meter. During outpatient consultations, a calculation was performed by subtracting the 
amount of doses used from the amount of doses prescribed for the $\operatorname{period}^{(9)}$.

For assessment of the inhalation technique, patients or their guardians were asked to demonstrate the usual form of use of their Inhalation Devices (ID). Patients' own demonstration was considered for adolescents and children over six years old who already used their medication without direct help from adults. For children under six years old, the parental or guardian demonstration was considered. For assessment of the inhalation technique steps, a checklist developed for the study was used, and a point was assigned to each correct answer thereby generating a 1-8 score. Based on the literature, seven different checklists were developed for this study according to the type of inhalation device used, as follows: Pressurized Inhaler (PI) alone ${ }^{(10)}$, PI with spacer and mask ${ }^{(11-12)}$, PI with spacer and mouthpiece (simple breathing technique $)^{(13)}$, dry powder PI with extension tube (Turbuhaler $\left.{ }^{\circledast}\right)^{(12)}$, capsule powder inhaler $\left(\text { Alenia }^{\circledast}\right)^{(3)}$, PI with spacer and mouthpiece (multiple breathing technique) ${ }^{(12)}$. Some inhalation technique errors were considered more serious because they directly affected the generation or lung deposition of the aerosol. These were called critical errors. The inhalation technique was considered correct if no critical errors were made in the demonstration ${ }^{(11)}$.

The assessment if the patient followed the required steps for using the inhalation device was accomplished. When these did not apply to the device used by the patient, no error was computed. For example: the step of shaking the inhalation device did not apply to patients using the powder inhaler therefore, not following it was not considered an error.

The following items were included in the assessment of the inhalation technique: shaking the device for 2-3 seconds; exhaling air from the lungs before inhaling the medication dose; maintaining effective inspiration of appropriate depth and vigor according to the device; apnea for 10 seconds or as long as possible after inhaling the medication dose; moving the device away from the mouth by $3 \mathrm{~cm}$; rinsing the mouth after using the inhaler device with $\mathrm{IC}$; assessing the conditions of the inhaler device: if it was age-appropriate, in perfect use conditions, without missing parts, or if there were any problems leading to loss of medication to the environment.

After recording the observations, the necessary orientations and corrections were provided. Control group patients had their inhalation technique observed and recorded by CEMAD staff members previously trained to use the checklists.

\section{ANALYSIS AND PROCESSING OF DATA}

The sample size was calculated, which allowed to detect the mean one unit-difference between the first and the second evaluation with a deviation of 0.9 . For detecting this difference between the two evaluations with $80 \%$ statistical power and 95\% confidence level, 26 patients would be necessary, 13 cases and 13 controls. According to the frequency distribution, means and/or medians were used. The Student's t-test, Fisher's exact, Yates correction chi-square, McNemar's chi-square, paired Student's t-test and Mann-Whitney tests were used to evaluate primary outcomes, when indicated. The final significance level was $\mathrm{p}<0.05$.

\section{ETHICAL ASPECTS}

The study was conducted between January and December 2016 and approved by the Research Ethics Committee (REC) of the Universidade Federal de Minas Gerais under number 1.369 .812 in 2015 , according to precepts of Resolution CNS 466/12 of the National Health Council on research with human beings. Brazilian Registry of Clinical Trials: RBR-8GZWZP. Children and adolescents and their guardians signed the Informed Consent form.

\section{RESULTS}

Figure 1 shows the flowchart of the study development.

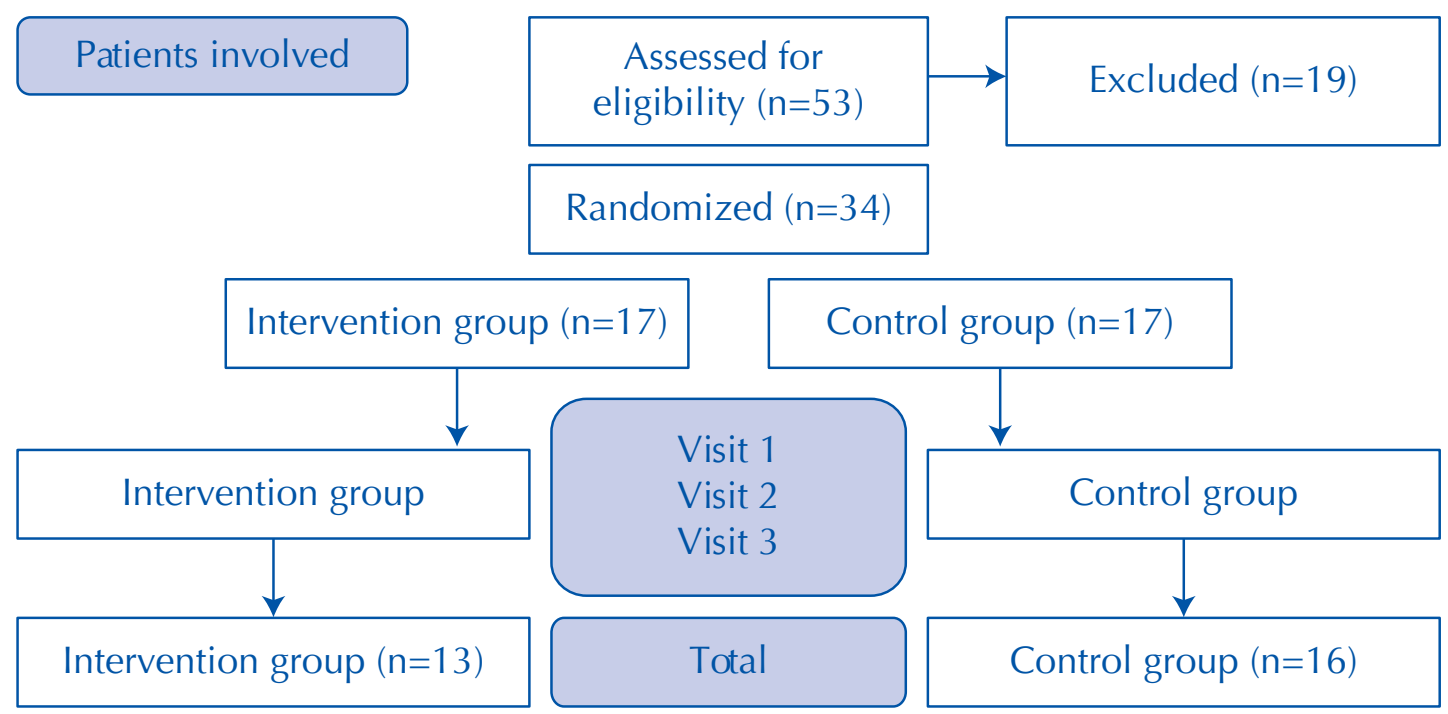

Figure 1 - Flowchart of the study development. 
The baseline characteristics of the intervention and control groups are described in Table 1.

As shown in Table 1, randomization allowed good comparability between cases and controls, and no statistically significant differences were found between the two groups, except for the ACT score. The chi-square test was used for categorical variables, the t-test was used for mean and standard deviation of continuous variables, and $p<0.005$ was considered significant.

The patients already had a long history of follow-up with a pediatric pulmonologist in secondary care, with a mean of 4.5 years for the intervention group and four years for the control group. The follow-up time at CEMAD was also long; an average of 2.5 years for the intervention group and
2.3 years for the control group. In addition, both the intervention group and the control group patients had already been using inhaled corticosteroids for a mean time of seven and 7.2 years, respectively.

In the analysis of adherence, there was no significant difference in adherence rates between evaluations for each group, as shown in Table 2.

Table 3 shows the scores of inhalation technique and critical errors in each evaluation performed for the control and intervention groups.

For the intervention group, the scores of inhalation technique and critical error elimination improved between evaluation 1 and 2 . This result was maintained in the third evaluation.

Table 1 - Baseline characteristics of intervention and control groups - Belo Horizonte, MG, Brazil, 2016.

\begin{tabular}{|c|c|c|c|c|c|c|c|}
\hline \multirow{2}{*}{ Variable } & \multicolumn{3}{|c|}{ Intervention $(n=13)$} & \multicolumn{3}{|c|}{ Control $(n=16)$} & \multirow{2}{*}{ p-value } \\
\hline & $\mathbf{n}$ & $\%$ & Mean $\pm \mathrm{SD}^{*}$ & $\mathbf{n}$ & $\%$ & Mean $\pm \mathrm{SD}^{*}$ & \\
\hline Male sex & 7 & 53.8 & & 7 & 43.7 & & 0.58 \\
\hline Age & & & $10.7 \pm 3.2$ & & & $10.3 \pm 4.4$ & 0.7 \\
\hline Uncontrolled environment & 3 & 23.0 & & 8 & 50.0 & & 0.2 \\
\hline Atopic & 12 & 92.3 & & 12 & 75.0 & & 0.2 \\
\hline ICU hospitalizationt & 3 & 23.0 & & 7 & 43.7 & & 0.4 \\
\hline Emergency consultations in the 12 prior months & 4 & 30.7 & & 7 & 43.7 & & 0.6 \\
\hline Critical error in IT‡ & 4 & 30.7 & & 5 & 31.2 & & 1.0 \\
\hline Measured adherence & 8 & & $52.1 \pm 45.3$ & 11 & & $58.4 \pm 47.2$ & 0.8 \\
\hline Reported adherence & 13 & & $74.8 \pm 43.0$ & 16 & & $71.5 \pm 42.9$ & 0.8 \\
\hline Inhalation technique & & & $5.9 \pm 1.8$ & & & $6.7 \pm 1.4$ & 0.2 \\
\hline Time of use of inhaled corticosteroids & & & $7.0 \pm 4.0$ & & & $7.2 \pm 4.4$ & 0.9 \\
\hline Secondary care follow-up (years) & & & $4.5 \pm 3.2$ & & & $4.0 \pm 3.2$ & 0.6 \\
\hline Time of hospitalization at the service & & & $2.5 \pm 1.3$ & & & $2.3 \pm 1.6$ & 0.7 \\
\hline Time between $1^{\text {st }}$ and $2^{\text {nd }}$ evaluation (days) & & & $35.8 \pm 10.6$ & & & $43.8 \pm 31.2$ & 0.3 \\
\hline Time between $2^{\text {nd }}$ e $3^{\text {rd }}$ evaluation (days) & & & $63.7 \pm 5.9$ & & & $70.5 \pm 33.5$ & 0.4 \\
\hline ACT $\S$ & & & $23.1 \pm 2.5$ & & & $18.5 \pm 5.1$ & 0.005 \\
\hline
\end{tabular}

*SD-standard deviation; +ICU-intensive care unit; ¥IT-inhalation technique; §ACT-Asthma Control Test

Table 2 - Reported and measured adherence rates to inhaled corticosteroids in children and adolescents with severe asthma in control and intervention groups - Belo Horizonte, MG, Brazil.

\begin{tabular}{|c|c|c|c|c|c|c|c|c|c|c|c|c|}
\hline \multirow{3}{*}{ Evaluation } & \multicolumn{6}{|c|}{ Intervention group } & \multicolumn{6}{|c|}{ Control group } \\
\hline & \multicolumn{3}{|c|}{ Reported adherence } & \multicolumn{3}{|c|}{ Measured adherence } & \multicolumn{3}{|c|}{ Reported adherence } & \multicolumn{3}{|c|}{ Measured adherence } \\
\hline & $\mathbf{n}$ & Median & $\mathbf{p}$ & $\mathbf{n}$ & Median & $\mathbf{p}$ & $\mathbf{n}$ & Median & $\mathbf{p}$ & $\mathbf{n}$ & Median & $\mathbf{p}$ \\
\hline 1 & 13 & 100 & $0.4^{*}$ & 8 & 64.5 & $0.2^{*}$ & 16 & 93 & $0.3^{*}$ & 11 & 85.0 & $0.7^{*}$ \\
\hline 2 & 13 & 86 & $0.9+$ & 11 & 94.0 & $0.8+$ & 16 & 96 & $0.9+$ & 8 & 92.5 & $0.3+$ \\
\hline 3 & 13 & 92 & & 10 & 96.5 & & 16 & 97 & & 9 & 98.0 & \\
\hline
\end{tabular}

${ }^{*}$ Comparison between evaluation 1 and 2; +Comparison between evaluation 2 and 3

Table 3 - Score of inhalation technique and critical error in inhalation technique of children and adolescents with severe asthma in intervention and control groups - Belo Horizonte, MG, Brazil.

\begin{tabular}{|c|c|c|c|c|c|c|c|c|c|c|}
\hline \multirow{3}{*}{ Evaluation } & \multicolumn{5}{|c|}{ Intervention group $(n=13)$} & \multicolumn{5}{|c|}{ Control group $(n=16)$} \\
\hline & \multicolumn{2}{|c|}{ IT score* } & \multicolumn{3}{|c|}{ Critical error in IT* } & \multicolumn{2}{|c|}{ IT score* } & \multicolumn{3}{|c|}{ Critical error in IT* } \\
\hline & Mean \pm SD $t$ & $\mathbf{p}$ & $\mathbf{n}$ & $\%$ & p & Mean \pm SD + & $\mathbf{p}$ & $\mathbf{n}$ & $\%$ & p \\
\hline Evaluation 1 & $5.9 \pm 1.8$ & $0.007 \ddagger$ & 4 & 30.7 & & $6.7 \pm 1.4$ & $0.3 \neq$ & 5 & 31.2 & $1.0 \neq$ \\
\hline Evaluation 2 & $7.6 \pm 0.7$ & $0.10 \S$ & 0 & & & $7.0 \pm 1.3$ & $0.13 \S$ & 4 & 25.0 & $1.0 \S$ \\
\hline Evaluation 3 & $7.9 \pm 0.3$ & & 0 & & & $7.4 \pm 0.8$ & & 5 & 31.2 & \\
\hline
\end{tabular}

*IT-inhalation technique; +SD-standard deviation; $\neq$ Evaluation 1 x evaluation 2 ; §Evaluation $2 \times$ evaluation 3 


\section{DISCUSSION}

Nurses' home visits were effective in raising scores of inhalation techniques and eliminating critical errors between the first and second evaluations, and such results were maintained in the third evaluation. Regarding outcomes of clinical control and adherence rates, there were no statistically significant changes.

Teaching the inhalation technique is a basic component of asthma management, because without the proper technique, symptom control may not be achieved ${ }^{(2)}$. The incorrect inhalation technique may reduce pulmonary deposition in the distal airway ${ }^{(3)}$ and checking it at all times is a strategic action to achieve the effective use of inhalation devices ${ }^{(13)}$. The aim of each step of the inhalation technique is the improvement of lung deposition or reduction of medication impaction in the upper airway, and its importance is described in the literature ${ }^{(11)}$.

In our study, despite the long follow-up at the service, about $30 \%$ of patients in both groups had critical errors in inhalation technique. The most frequent critical error was not moving the device away from the mouth by 2-3 $\mathrm{cm}$ before starting its use, found in $100 \%$ of evaluations. However, this critical error applied to only $13.7 \%$ of patients using the pressurized inhaler without the aid of a spacer or extension. In $31.5 \%$ of patients, the error of not breathing out before using the medication was found, followed by errors in inspiration, such as inadequate speed or depth, present in $27.5 \%$ of patients, and failure to perform apnea after inhaling the medication, found in $11 \%$ of patients.

In a clinical trial, the effects of a program directed at children with asthma were evaluated ${ }^{(5)}$. The intervention group received quarterly consultations with the pediatric pulmonologist, education, and nurses' home visits. The control group received outpatient consultations at the same frequency and maintained follow-up with a pediatrician of Primary Health Care (PHC). Baseline data showed the presence of incorrect inhalation technique in $66.7 \%$ of patients in the intervention group and $53.3 \%$ in the control group. After the intervention phase of the study, there was a significant improvement $(p=0.0005)$ in the inhalation technique of the intervention group ${ }^{(5)}$.

In the present study, the baseline percentage of inhalation technique errors was lower, perhaps because our patients had already been in follow-up with the specialized service for a long period. Since the control group received the same guidance on inhalation technique in outpatient consultations, a possible speculation is that these outcomes are a consequence of the intervention performed. The third evaluation of the inhalation technique occurred after 60 days, thereby showing complete remission of critical errors in the control group.

In our study, the percentage of patients with incorrect inhalation technique at the beginning of the study was $30.7 \%$ in the intervention group and $31.2 \%$ in the control group. In the intervention group, there was a significant improvement $(p=0.007)$ in the inhalation technique, which did not occur in the control group. The use of scores has been discussed and a recent work highlighted that identifying patients with correct or incorrect inhalation technique is more useful than using scores alone ${ }^{(14)}$.

Scores have been used in studies involving adults and based on the use of checklists that rate patients' performance of the inhalation technique ${ }^{(15)}$. In our study, the mean baseline score of inhalation technique was 5.9 for the intervention group and 6.7 for the control group.

A clinical trial involving adolescents with asthma was conducted with the aim to evaluate the effects of using an interactive video intervention for teaching the inhalation technique $^{(16)}$. The control group received education on inhalation technique from written material. That study did not provide information on treatment time and used an eight-step checklist for assessment of the inhalation technique. One point was computed for each correct answer, and no cutoff point was established to determine the correct or incorrect inhalation technique. The results showed that $20 \%$ of patients had never received guidance on the inhalation technique, and $59 \%$ of participants received this orientation in less than three occasions. The treatment time was not informed. The baseline score of inhalation technique was 3.08 in the intervention group and 4.05 in the control group. There was a statistically significant improvement $(\mathrm{p}<0.001)$ in the score of inhalation technique in the group receiving education by video.

The baseline scores of our study were higher, perhaps because patients already had a long follow-up time when they were admitted. As the assessment of inhalation technique is a basic component of asthma treatment ${ }^{(2)}$, unlike patients in the other study ${ }^{(16)}$, our patients had more prior opportunities of learning it.

A cutoff point was not adopted for the assessment of inhalation technique as appropriate or inappropriate. As seven different checklists were used and they covered the various possible forms of using inhalation devices, it would be difficult to establish a global score with clinical applicability.

Surprisingly, in our study, the improvement in inhalation technique was not accompanied by clinical improvement measured by the ACT. The inflammatory process may affect even the distal areas, which could hinder the penetration of the drug. Thus, despite the correct inhalation technique, some patients would not have clinical improvement only with the appropriate use of IC. In addition, clinical control was measured only by the ACT and, according to ATS recommendations ${ }^{(6)}$, it involves other variables, such as airflow limitation shown by forced expiratory volume in the first second (FEV1) below 80\% of the total predicted, a variable which was not measured in this study. Although the ACT is a validated instrument ${ }^{(8)}$ and performs well in the absence of FEV1, the best measure for severe asthma would be a combination of both ${ }^{(8)}$.

For the measures of adherence to the use of IC, none of the groups showed improvement. Adherence is multifactorial and directly impacted by several factors that were not the target of this study, such as patients' beliefs about their health, fear of side effects and relationship with the team $^{(9,17)}$. The recommended adherence measurement strategy is a multi-method approach combining patients' reports and objective measurements ${ }^{(9)}$. These recommendations are 
adopted in CEMAD and were followed in the design of this study. Although there were no significant changes in adherence rates, they were already high for our patients. In the intervention group, the baseline adherence rate was $64.5 \%$ (median of eight out of 13 patients), which may have influenced the outcome. In the second evaluation of this same group, when adherence was measured in 11 patients, the adherence rate increased to $94 \%$. Asthma studies have documented adherence rates of 30 to $70 \%{ }^{(18)}$. These data reinforce the high adherence rates obtained in our study.

Adherence rates above $80 \%$ are associated with better asthma control ${ }^{(19)}$ and in Brazil, adherence rates of controlled and uncontrolled asthmatic children were 85.5 and $33.8 \%$, respectively ${ }^{(9)}$.

In the present study, the high adherence rates were not related to improvement in clinical control evaluated by the ACT. However, critically ill patients may have different asthma phenotypes and need other controllers than only IC associated with long-acting bronchodilator ${ }^{(6)}$.
A limitation of this work was the sample size. Severe asthma is a rare condition and our patients, selected from a referral outpatient clinic, reflect the population of children referred to tertiary care by secondary care because of failure to control asthma. They already have a long treatment time, are diagnosed as severe asthma, and some are considered refractory to treatment. Multicenter prospective studies could contribute to further evaluations, including pharmacological, possibly in partnerships with funding institutions and industries.

Home visits are a resource often used in primary care services, but given the results and potential benefits, they should be recommended in tertiary care for selected patients.

\section{CONCLUSION}

Home visits were effective in raising inhalation technique scores and eliminating critical errors in children and adolescents with severe asthma. In tertiary care, this should be considered for selected patients.

\section{RESUMO}

Objetivo: Avaliar a eficácia da visita domiciliar, em um grupo de crianças e adolescentes com asma grave, utilizando o escore da técnica inalatória e as taxas de adesão ao tratamento medicamentoso. Método: Estudo experimental randomizado controlado, com duração de 12 meses, envolvendo pacientes, com idades entre três e 17 anos, acompanhados regularmente em um ambulatório de pneumologia pediátrica de um hospital universitário da região Sudeste do Brasil. Um grupo de pacientes recebeu apenas consultas ambulatoriais e o outro grupo, além das consultas ambulatoriais, recebeu visitas da enfermeira no domicílio. Foram analisadas as diferenças entre os grupos nos desfechos: escores da técnica inalatória e taxa de adesão ao tratamento. Resultados: Participaram 29 pacientes. No grupointervenção, houve aumento estatisticamente significante dos escores da técnica inalatória $(\mathrm{p}<0,05)$ e eliminação de erros críticos da primeira para a segunda avaliação, resultados que foram mantidos na terceira. Não houve alterações significativas na técnica inalatória do grupo-controle. As taxas de adesão ao tratamento medicamentoso em ambos os grupos não se elevaram. Conclusão: A visita domiciliar foi eficaz em melhorar os escores de técnica inalatória em pacientes com asma grave. Registro Brasileiro de Ensaios Clínicos: RBR8GZWZP

\section{DESCRITORES}

Asma; Visita Domiciliar; Criança; Adolescente; Adesão à Medicação; Inalação.

\section{RESUMEN}

Objetivo: Evaluar la efectividad de la visita domiciliaria en un grupo de niños y adolescentes con asma severa, utilizando el score de la técnica inhalatoria y las tasas de adhesión al tratamiento medicamentoso. Método: Estudio experimental randomizado controlado, con duración de 12 meses, que incluyó a pacientes con edades entre tres y 17 años, acompañados regularmente en un ambulatorio de neumología pediátrica de un hospital universitario de la región Sureste de Brasil. Un grupo de pacientes recibió solo consultas ambulatorias y el otro grupo, además de las consultas ambulatorias, recibió visitas de la enfermera en el hogar. Fueron analizadas las diferencias entre los grupos en los resultados: scores de la técnica inhalatoria y tasa de adhesión al tratamiento. Resultados: Participaron 29 pacientes. En el grupo intervención, hubo aumento estadísticamente significativo de los scores de la técnica inhalatoria ( $<<0,05)$ y eliminación de errores críticos de la primera a la segunda evaluación, resultados que se mantuvieron en la tercera. No hubo modificaciones significativas en la técnica inhalatoria del grupo de control. Las tasas de adhesión al tratamiento medicamentoso en ambos grupos no se elevaron. Conclusión: La visita domiciliaria fue eficaz en mejorar los scores de técnica inhalatoria en pacientes con asma severa. Registro Brasileño de Ensayos Clínicos: RBR-8GZWZP

\section{DESCRIPTORES}

Asma; Visita Domiciliaria; Niño; Adolescente; Cumplimiento de la Medicación; Inhalación.

\section{REFERÊNCIAS}

1. Guilbert TW, Bacharier LB, Fitzpatrick AM. Severe asthma in children. J Allergy Clin Immunol Pract. 2014;2(5):489-500. DOI: https://doi. org/10.1016/j.jaip.2014.06.022

2. Groot EP, Kreggemeijer WJ, Brand PL. Getting the basics right resolves most cases of uncontrolled and problematic asthma. Acta Paediatr. 2015;104(9):916-21. DOI: https://doi.org/10.1111/apa.13059

3. Sanchis J, Gich I, Pedersen S; Aerosol Drug Management Improvement Team (ADMIT). Systematic review of errors in inhaler use: has patient technique improved over time? Chest. 2016 Aug;150(2):394-406. DOI: https://doi.org/10.1016/j.chest.2016.03.041

4. Bracken M, Fleming L, Hall P, Van Stiphout N, Bossley C, Biggart E, et al. The importance of nurse-led home visits in the assessment of children with problematic asthma. Arch Dis Child. 2009;94(10):780-4. DOI: 10.1136/adc.2008.152140

5. Hughes DM, McLeod M, Garner B, Goldbloom RB. Controlled trial of a home and ambulatory program for asthmatic children. Pediatrics. 1991;87(1):54-61. 
6. Chung KF, Wenzel SE, Brozek JL, Bush A, Castro M, Sterk PJ, et al. International ERS/ATS guidelines on definition, evaluation and treatment of severe asthma. Eur Respir J. 2014;43(2):343-73. DOI: https://doi.org/10.1183/09031936.00202013

7. Liu AH, Zeiger R, Sorkness C, Mahr T, Ostrom N, Burgess S, et al. Development and cross-sectional validation of the Childhood Asthma Control Test. J Allergy Clin Immunol. 2007;119(4):817-25. DOI: https://doi.org/10.1016/j.jaci.2006.12.662

8. Nathan RA, Sorkness CA, Kosinski M, Schatz M, Li JT, Marcus P, et al. Development of the asthma control test: a survey for assessing asthma control. J Allergy Clin Immunol. 2004;113(1):59-65. DOI: https://doi.org/10.1016/j.jaci.2003.09.008

9. Lasmar L, Camargos P, Champs NS, Fonseca MT, Fontes MJ, Ibiapina C, et al. Adherence rate to inhaled corticosteroids and their impact on asthma control. Allergy. 2009;64(5):784-9. DOI: https://doi.org/10.1111/j.1398-9995.2008.01877.x

10. Alexander DS, Geryk L, Arrindell C, DeWalt DA, Weaver MA, Sleath B, et al. Are children with asthma overconfident that they are using their inhalers correctly? J Asthma. 2016;53(1):107-12. DOI: https://doi.org/10.3109/02770903.2015.1057848

11. Walia M, Paul L, Satyavani A, Lodha R, Kalaivani M, Kabra SK. Assessment of inhalation technique and determinants of incorrect performance among children with asthma. Pediatr Pulmonol. 2006;41(11):1082-7. DOI: https://doi.org/10.1002/ppul.20498

12. Kamps AW, Brand PL, Roorda RJ. Determinants of correct inhalation technique in children attending a hospital-based asthma clinic. Acta Paediatr. 2002;91(2):159-63.

13. Burkhart PV, Rayens MK, Bowman RK. An evaluation of children's metered-dose inhaler technique for asthma medications. Nurs Clin North Am. 2005;40(1):167-82. DOI: https://doi.org/10.1016/j.cnur.2004.08.010

14. Normansell R, Kew KM, Mathioudakis AG. Interventions to improve inhaler technique for people with asthma. Cochrane Database Syst Rev. 2017;13(3):CD012286. DOI: https://doi.org//10.1002/14651858.CD012286.pub2

15. Zambelli-Simões L, Martins MC, Possari JCC, Carvalho GB, Coelho ACC, Cipriano SL, et al. Validation of scores of use of inhalation devices: valoration of errors. J Bras Pneumol. 2015;41(4):312-22. DOI: http://dx.doi.org/10.1590/S1806-37132015000004435

16. Bynum A, Hopkins D, Thomas A, Copeland N, Irwin C. The effect of telepharmacy counseling on metered-dose inhaler technique among adolescents with asthma in rural Arkansas. Telemed J E Health. 2001;7(3):207-17.

17. Price D, Bosnic-Anticevich S, Briggs A, Chrystyn H, Rand C, Scheuch G, et al. The Inhaler Error Steering Committee: inhaler competence in asthma: common errors, barriers to use and recommended solutions. Respir Med. 2013;107(1):37-46. DOI: https://doi.org/10.1016/j. rmed.2012.09.017

18. Rottier BL, Rubin BK. Asthma medication delivery: mists and myths. Paediatr Respir Rev. 2013;14(2):112-8. DOI: https://doi.org/10.1016/j. prrv.2013.02.013

19. Klok T, Kaptein AA, Duiverman EJ, Brand PL. It's the adherence, stupid (that determines asthma control in preschool children)! Eur Respir J. 2014;43(3):783-91. DOI: https://doi.org/10.1183/09031936.00054613 